\title{
ORIGINAL ARTICLE Biopsychosocial outcomes in individuals with and without spinal cord injury: a Swiss comparative study
}

\author{
S Geyh ${ }^{1,2}$, E Nick $^{3}$, D Stirnimann ${ }^{4}, S$ Ehrat ${ }^{5}, \mathrm{R}$ Müller ${ }^{1,6}$ and F Michel ${ }^{7}$
}

Study design: Multicentre controlled study.

Objectives: To investigate if individuals with and without spinal cord injury (SCl) differ in biopsychosocial variables according to the International Classification of Functioning, Disability and Health (ICF).

Setting: Participants were recruited through three major $\mathrm{SCl}$ rehabilitation centres in Switzerland.

Methods: A convenience sample of people with $\mathrm{SCl}(N=102)$ and a matched non-SCl sample $(N=73)$ were compared according to secondary conditions, pain, depressive symptoms, participation, social support, self-efficacy, self-esteem, coping and sense of coherence. Difference tests and multivariate logistic regression analyses to predict the likelihood of group membership were calculated.

Results: People with $\mathrm{SCl}$ reported more health conditions, higher levels of anxiety and depressive symptoms, worse pain and pain interference, lower level of participation and social support, lower self-efficacy, self-esteem and task- and emotion-oriented coping. The two samples did not differ in satisfaction with social support, in use of avoidance-oriented coping and in sense of coherence. Health conditions, pain interference, participation and age were found to be significant predictors of the likelihood of group membership. In the logistic regression models, the number of health conditions, limitations due to health conditions, pain interference, participation, task-oriented coping and age are significant predictors of group membership, accounting for $55 \%$ of variation.

Conclusion: Health conditions, pain interference and participation seemed to be the areas of biopsychosocial functioning that are substantially influenced by SCl. Potential buffering resources seem to be diminished in individuals with SCl. In rehabilitation practice, prevention of secondary conditions, treatment of pain, enhancement of participation and strengthening resources should be addressed. Spinal Cord (2012) 50, 614-622; doi:10.1038/sc.2012.21; published online 13 March 2012

Keywords: spinal cord injuries; self-efficacy; self-esteem; participation

\section{INTRODUCTION}

Spinal cord injury (SCI) affects the body and the psychological state of the individual, everyday activities as well as societal participation. Thus, understanding disability following SCI requires a multidimensional, biopsychosocial approach, which is provided by the framework of the International Classification of Functioning, Disability and Health - (ICF; Figure 1). ${ }^{1}$

Beside sensory, motor and functional losses, SCI can be coupled, for example, with pain, depression or social isolation, which can affect physical and mental health, participation and quality of life..$^{2-4}$ Similar problems can be observed in non-SCI populations as well. Disability represents a universal experience that affects all humans at some point in their lives to a certain degree. ${ }^{5}$ Thus, one could ask: How do people with SCI differ from those without SCI?

Pain, for example, is reported in 26 to $96 \%$ of individuals with SCI. ${ }^{6}$ In the general population, chronic pain occurred in $25-50 \%$ of surveyed individuals. ${ }^{7}$ It has been estimated that up to one-third of individuals with SCI are at risk for depression. ${ }^{8}$ In the United States, the lifetime prevalence of mental disorders is expected to be $\sim 50 \%$ in the general population. ${ }^{9}$ Considering social relations, it has been shown that individuals with $\mathrm{SCI}$ have at least 4 reliable support persons and an average network size of 25 people. ${ }^{10,11}$ In the general population, network sizes range between 10 and 18 people with 3-6 close relations. $^{12}$

Most of the studies comparing individuals with SCI vs non-SCI focus on medical issues (for example, hypertonia or spinal reflex). Reviews reveal that individuals with SCI tend to report lower quality of life and life satisfaction than non-SCI controls. ${ }^{13}$ Depressive disorders $^{14}$ and pain perception was compared between individuals with and without SCI on a body function and structure level,,${ }^{15}$ but only few studies compare SCI with non-SCI individuals in relation to psychosocial aspects.

In addition, the existing studies do not tell how the 'bio', the 'psycho' and the 'social' aspects contribute to functioning following SCI. Referring to the model of the ICF, all components of functioning, namely health conditions, body functions, activity and participation, environmental and personal factors as well as their interrelations, should be taken into account. In comparing individuals with and without SCI comprehensively, considering the different dimensions of functioning and disability helps to understand in more specific ways how a traumatic event like SCI affects the person. Comparisons between different samples and different aspects of disability might

${ }^{1}$ Swiss Paraplegic Research (SPF), Nottwil, Switzerland; ${ }^{2}$ Department of Health Sciences and Health Policy, University of Lucerne and SPF, Nottwil, Switzerland; ${ }^{3}$ Zurich University of Applied Sciences, Zurich, Switzerland; ${ }^{4}$ University Hospital Balgrist, Paraplegic Center, Zurich, Switzerland; ${ }^{5}$ REHAB Basel, Swiss Paraplegic Center, Basel, Switzerland; ${ }^{6}$ Institute for Health and Rehabilitation Sciences, Ludwig-Maximilians-University, Munich, Germany and ${ }^{7}$ Swiss Paraplegic Centre (SPZ), Nottwil, Switzerland Correspondence: Dr S Geyh, Swiss Paraplegic Research, Guido A. Zäch Strasse 4, CH-6207 Nottwil, Switzerland.

E-mail: szilvia.geyh@paranet.ch

Received 22 September 2011; revised 24 January 2012; accepted 10 February 2012; published online 13 March 2012 
advise goal setting, treatment planning and delivery in clinical rehabilitation.

The objective of the study is to compare individuals with and without SCI from a comprehensive biopsychosocial perspective, taking into account the various components of functioning and disability. The specific aims are: (1) to investigate if samples of individuals with and without SCI differ in selected biopsychosocial variables in respect of health conditions, body functions, activity and participation, environmental and personal factors; and (2) to explore the differences between individuals with and without SCI adjusting for the relations between health conditions, body functions, activity and participation and environmental and personal factors.

\section{METHODS}

\section{Study design}

A multicentre cross-sectional study was conducted including people with SCI living in the community, and a hospital-based staff comparison group without SCI. The recruitment of the SCI sample as well as the non-SCI sample was carried out through three major SCI rehabilitation centres in Switzerland (University Hospital Balgrist, Paraplegic Centre, Zurich; Swiss Paraplegic Centre, REHAB Basel; Swiss Paraplegic Centre (SPZ), Nottwil). The design and materials of the study were approved by the local ethics committees.

\section{Participants}

Individuals were eligible for participation in the SCI sample if they have sustained an SCI because of injury, iatrogenic or comiogenic causes (for example, surgical procedures, radiation or medical complication), or because

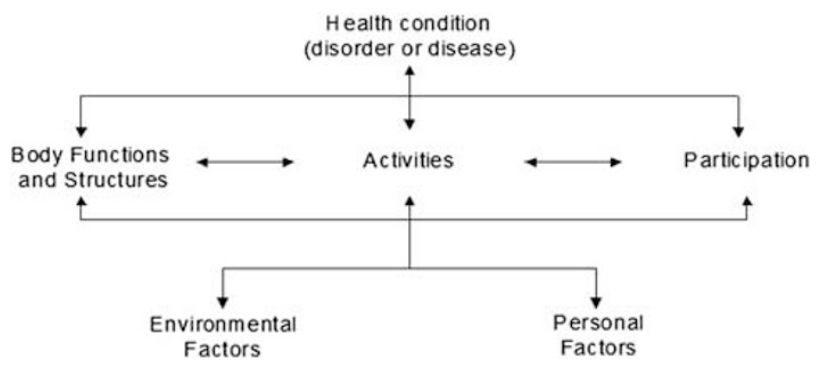

Figure 1 The biopsychosocial model of functioning, disability and health. of acute nonprogressive diseases (for example, infection, bleeding, ischaemic event). German-speaking individuals of $\geqslant 18$ years were included who have been living in the community between 6 months and 5 years at the beginning of the data collections. Participants had to sign an informed consent form. Individuals were excluded if they had a progressive neurological disorder, a neoplasm of the spine or a concurrent neurological condition that affected mental functions, for example, traumatic brain injury, cerebral ischaemia or intracerebral haemorrhage.

The non-SCI comparison sample consisted of medical as well as nonmedical staff of the cooperating rehabilitation facilities employed in any position and recruited according to age, gender and educational level to match the individuals in the SCI sample.

\section{Instruments, materials and procedures}

Data were collected by self-report questionnaires sent to the eligible participants by postal mail. The questionnaires were selected to cover all components of the biopsychosocial model of ICF: health conditions, body functions, participation and environmental and personal factors (Table 1). The questionnaires used were the Self-Report Health Conditions Scale (SHCS), the Brief Pain Inventory (BPI), ${ }^{16}$ the Hospital Anxiety and Depression Scale (HADS), ${ }^{17}$ Reintegration to Normal Living Index (RNLI), ${ }^{18}$ Short Form Social Support Questionnaire (SSQ6), ${ }^{19}$ the General Self-Efficacy Scale (GSE), ${ }^{20}$ the Rosenberg Self-Esteem Scale (RSES), ${ }^{21}$ Coping Inventory for Stressful Situations (CISS-21) ${ }^{22}$ and the Sense of Coherence Scale (SOC). ${ }^{23}$

In addition, the following sociodemographic and injury-related variables were documented: age, gender, marital status, level of education, employment status, date of event, aetiology and level and completeness of injury.

\section{Analyses}

To investigate if samples of individuals with and without SCI differ in the selected biopsychosocial variables, the questionnaire scores were compared using independent $t$-tests or Mann-Whitney $U$-test. To quantify the effect sizes, Cohen's $d$ is reported. Cohen's $d$ is considered large at 0.8 , moderate at 0.5 and small at 0.2 .

To explore the differences between individuals with and without SCI in a multivariate model adjusting for the different biopsychosocial factors, classificatory logistic regression was used with SCI versus non-SCI as dependent variable and dichotomized independent variables. For dichotomization, the median of each variable was used as a cutoff. Missing values in the variables 'pain intensity (past $24 \mathrm{~h}$ )' and 'limitations due to health condition' have been coded ' 0 -absent' for the regression analyses.

Table 1 Study variables and measurement instruments

\begin{tabular}{|c|c|c|c|c|c|c|}
\hline ICF components & Measurement instruments & Subscales/subscores & Abbreviations & $\begin{array}{l}\text { Number } \\
\text { of items }\end{array}$ & Scoring & $\begin{array}{l}\text { Scoring } \\
\text { range }\end{array}$ \\
\hline \multirow[t]{2}{*}{ Health condition } & \multirow[t]{2}{*}{ Self-Report Health Conditions Scale } & Number of health conditions & SHCS-N & 19 & Summary score & $0-19$ \\
\hline & & $\begin{array}{l}\text { Limitations due to health } \\
\text { conditions }\end{array}$ & SHCS-L & 19 & Mean & $1-4$ \\
\hline \multirow[t]{2}{*}{ Body functions } & \multirow[t]{2}{*}{ Hospital Anxiety and Depression Scale ${ }^{17}$} & Anxiety symptoms & HADS-A & 7 & Summary score & $0-21$ \\
\hline & & Depression symptoms & HADS-D & 7 & Summary score & $0-21$ \\
\hline \multirow[t]{2}{*}{ Body functions } & \multirow[t]{2}{*}{ Brief Pain Inventory ${ }^{16}$} & Pain intensity (past 24 h) & BPI-Intens & 4 & Mean & $0-10$ \\
\hline & & Pain interference & BPI-Interfere & 7 & Mean & $0-10$ \\
\hline Participation & Reintegration to Normal Living Index ${ }^{18}$ & - & RNLI & 11 & Summary score & $10-100$ \\
\hline \multirow[t]{2}{*}{ Environmental factors } & \multirow[t]{2}{*}{ Short-Form Social Support Questionnaire-6 $6^{19}$} & Number of support persons & SSQ-N & 6 & Mean & $0-9$ \\
\hline & & Satisfaction with support & SSQ-S & 6 & Mean & $1-6$ \\
\hline Personal factors & General Self-Efficacy Scale 20 & - & GSE & 10 & Summary score & $10-40$ \\
\hline Personal factors & Rosenberg Self-Esteem Scale ${ }^{21}$ & - & RSES & 10 & Summary score & $0-30$ \\
\hline \multirow[t]{3}{*}{ Personal factors } & \multirow[t]{3}{*}{ Coping Inventory for Stressful Situations- $21^{22}$} & Task-oriented coping & CISS-T & 7 & Mean & $1-5$ \\
\hline & & Emotion-oriented coping & CISS-E & 7 & Mean & $1-5$ \\
\hline & & Avoidance-oriented coping & CISS-A & 7 & Mean & $1-5$ \\
\hline Personal factors & Sense of Coherence Scale-13 ${ }^{23}$ & - & SOC & 13 & Summary score & $13-91$ \\
\hline
\end{tabular}


Both theory-based and exploratory regression models were calculated. In the theory-based approach, independent variables from each ICF component were preselected based on the significance of $\chi^{2}$ tests, and entered in separate models first, that is, one model for health conditions, one model for body functions, and so on. The final model enclosed all variables, which were significant in the separate models. In the exploratory approach, two models were run including all independent variables, first in a stepwise selection model, and second in a 'forced-in' model without selection.

Model diagnostics included testing for multicollinearity with the variation inflation factor and for independence of residuals with the Durbin- Watson test.

\section{RESULTS}

In three facilities, 557 individuals with SCI were screened for eligibility, 394 individuals were invited to participate in the study and a convenience sample of 102 individuals responded to the questionnaires (response rate: 25.9\%; Figure 2). For the non-SCI sample, 195 employees of the study centres were contacted and 73 of them participated (response rate 37.4\%; Figure 3).

The sociodemographic and lesion-related characteristics of the study participants are depicted in Table 2. The SCI and the non-SCI sample did not differ in gender distribution, but in the SCI sample, people were on average 7.1 years older and had 2.2 years less of formal education compared with the non-SCI participants. Whereas $100 \%$ of the non-SCI group were employed, $45 \%$ of the SCI sample worked in a paid employment.

Table 3 summarizes the questionnaire scores and the results of the difference tests between the SCI and the non-SCI sample. From the 15 questionnaire scores, all but 3 showed statistically significant differences between the samples. People with SCI reported more health conditions and more limitations due to these health conditions than people in the non-SCI sample. Considering body functions, they showed higher levels of anxiety and depressive symptoms, worse pain and more pain interference than people without SCI. The level of participation of individuals with SCI was significantly lower than of the comparison group. Considering environmental factors, a lower number of support providers was available to individuals with SCI. At the level of personal factors, self-efficacy and self-esteem were significantly lower and task-oriented and emotion-oriented coping significantly less used compared with the non-SCI sample. The two samples did not differ significantly in their satisfaction with the available social support, in their use of avoidance-oriented coping strategies and in their sense of coherence.

According to the effect size, the largest differences were observed in pain interference $(d=-1.9)$, in the number of health conditions $(d=-1.4)$, in the level of participation $(d=1.4)$ and in the interference due to health conditions $(d=-1.2)$. Differences between the SCI and the non-SCI sample were also large in depressive symptoms $(d=-0.9)$, pain intensity $(d=-0.9)$ and self-esteem $(d=0.9)$.

Before entering the logistic regression models, all independent variables were dichotomized using the median value as cutoff. The results of the dichotomization and the testing of the differences between the SCI and the non-SCI samples are shown in Table 4. Pain intensity, satisfaction with social support, self-efficacy, avoidanceoriented coping, sense of coherence and gender were not significantly different between the samples after dichotomization and therefore did not enter the theory-based logistic regression analyses.

The results of the multivariate logistic regression analyses are summarized in Table 5. The following independent variables arouse as statistically significant from the separate models for each ICF component: (1) the number of health conditions; (2) from body functions: symptoms of anxiety and depression and pain interference;

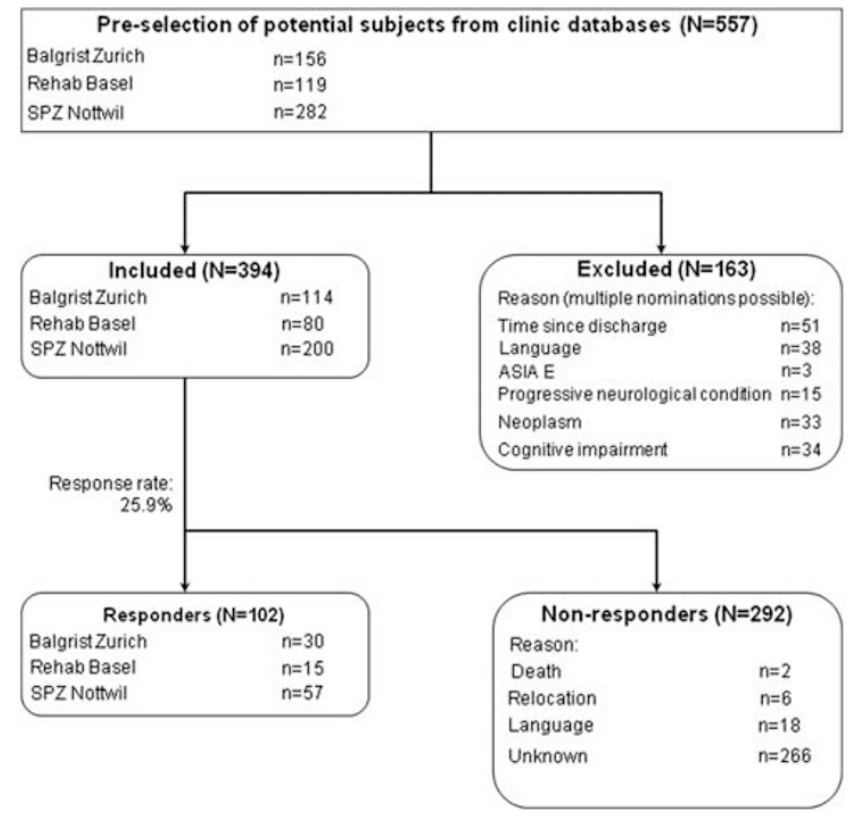

Figure 2 Recruitment of study participants for the SCI sample.

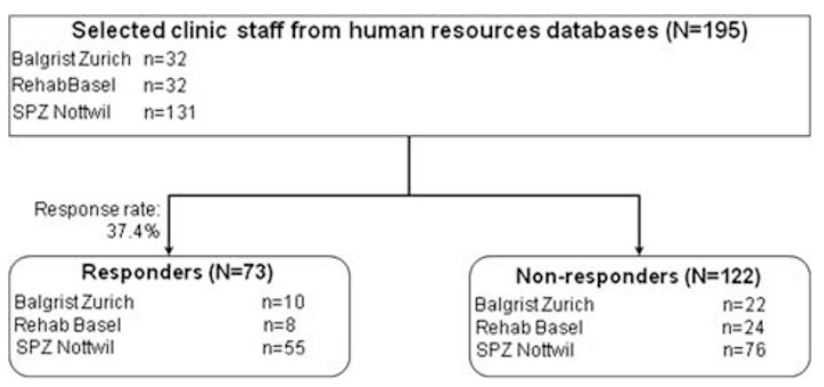

Figure 3 Recruitment of study participants for the non-SCI sample.

(3) participation; (4) from the component of environmental factors: social support quantity; (5) from the component of personal factors: task-oriented coping; (6) age and years of education from the sociodemographic variables. These variables entered the final model and four proved to be significant predictors of the likelihood of group membership (SCI versus non-SCI), namely, number of health conditions $(\beta=2.05$, s.e. $=0.53, P=0.00)$, pain interference $(\beta=2.37$, s.e. $=0.58, P=0.00)$, participation $(\beta=-1.80$, s.e. $=0.55, P=0.00)$ and age $(\beta=1.47$, s.e. $=0.56, P=0.01)$. This final model was significant $\left(\chi^{2}=105.77\right.$, d.f. $\left.=8, P=0.00\right)$ and improved the prediction of group membership compared with an empty model by $49 \%$ $\left(R^{2}\right.$ Cox-Snell $\left.=0.49\right)$. According to the odds ratios (ORs) from the final model, an individual who reported pain interference was 11 times more likely to be a member of the SCI than the non-SCI group ( $\mathrm{OR}=10.69,95 \%$ confidence interval (95\% CI=3.42-33.45). An individual with more health conditions was 8 times more likely $(\mathrm{OR}=7.74,95 \% \mathrm{CI}=2.75-21.78)$, with low levels of participation 6 times more likely $(\mathrm{OR}=0.17,95 \% \mathrm{CI}=0.06-0.49)$, and with higher age 4 times more likely $(\mathrm{OR}=4.33,95 \% \mathrm{CI}=1.45-12.96)$ to be from the SCI than the non-SCI sample.

In addition to the logistic regression analyses based on the biopsychosocial model of ICF, explorative models have also been calculated for comparison. The results of the explorative logistic regression 
Table 2 Sociodemographic and SCl-related characteristics of the SCl sample $(n=102)$, sociodemographic characteristics of the non-SCI sample $(n=73)$ and their comparison

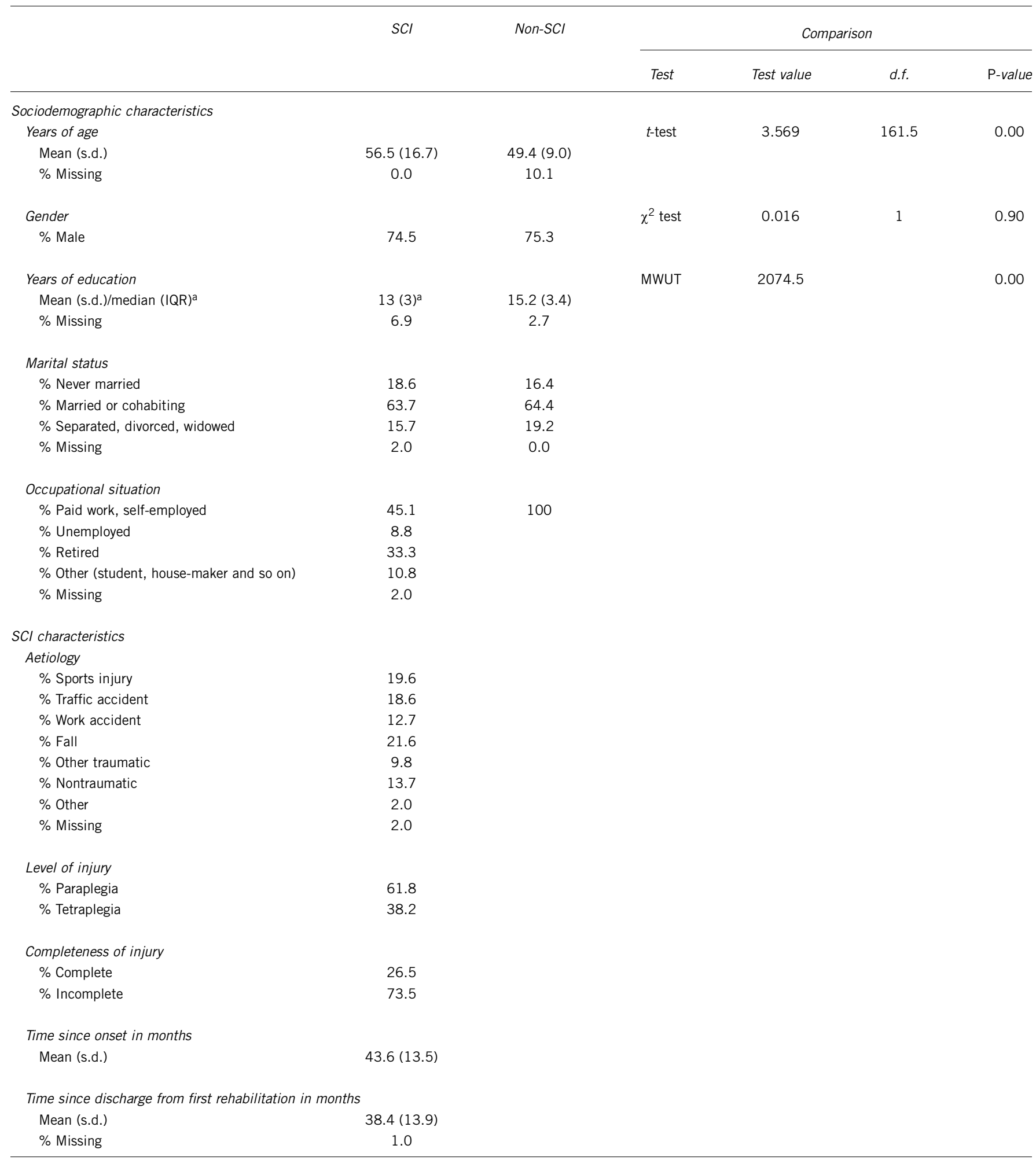

Abbreviations: d.f., degree of freedom; IQR, interquartile range; MWUT, Mann-Whitney U-test; SCI, spinal cord injury.

${ }^{a}$ Median and IQR are reported due to a significant Kolmogorov-Smirnov test $(\alpha<0.01)$.

analyses with group membership (SCI versus non-SCI) as dependent variable are shown in Table 6. The results of the stepwise and the forced-in approach are similar in terms of the variables arising as significant predictors. In both models, the number of health conditions, limitations due to health conditions, pain interference, participation, task-oriented coping and age are significant predictors. In the 
Table 3 Questionnaire results and bivariate differences between the $\mathrm{SCl}$ and the non-SCI samples

\begin{tabular}{|c|c|c|c|c|c|c|c|c|c|c|c|c|}
\hline \multirow[t]{2}{*}{ Variable } & \multirow[t]{2}{*}{ Scale } & \multicolumn{3}{|c|}{$\mathrm{SCl}$} & \multicolumn{3}{|c|}{ Non-SCl } & \multicolumn{4}{|c|}{ Difference test } & \multirow{2}{*}{$\frac{\text { Effect size }}{\text { Cohen's d }}$} \\
\hline & & $\mathrm{n}$ & $M / M D^{a}$ & s.d./IQR & $n$ & $M / M D^{a}$ & s.d./IQR & Test & Test value & d.f. & $\mathrm{P}$-value & \\
\hline Health conditions-number & SHCS-N & 76 & 5.0 & 3.1 & 67 & 1.6 & 1.5 & $t$-test & 8.41 & 110.73 & $0.00 *$ & -1.4 \\
\hline Health conditions-limitations & SHCS-L & 37 & 1.8 & 0.8 & 26 & $1.1^{\mathrm{a}}$ & $0.1^{\mathrm{b}}$ & MWUT & 108.50 & & $0.00 *$ & -1.2 \\
\hline Anxiety symptoms & HADS-A & 97 & 5.9 & 4.2 & 72 & 3.5 & 2.8 & $t$-test & 4.37 & 165.44 & $0.00 *$ & -0.7 \\
\hline Depression symptoms & HADS-D & 96 & 5.9 & 3.6 & 72 & 3.0 & 2.4 & $t$-test & 6.30 & 164.30 & $0.00 *$ & -0.9 \\
\hline Pain intensity (last 24 h) & BPI-Intens & 38 & 1.7 & 1.8 & 62 & $0.5^{\mathrm{a}}$ & $0.3^{b}$ & MWUT & 645.00 & & $0.00^{*}$ & -0.9 \\
\hline Pain interference & BPI-Interfere & 98 & 2.9 & 2.1 & 66 & $0.0^{a}$ & $0.4^{b}$ & MWUT & 782.50 & & $0.00 *$ & -1.9 \\
\hline Participation & RNLI & 94 & 78.2 & 19.1 & 72 & $98.2^{\mathrm{a}}$ & $6.6^{b}$ & MWUT & 1337.50 & & $0.00 *$ & 1.4 \\
\hline Social support-number & SSQ-N & 93 & 2.7 & 2.0 & 72 & 3.3 & 1.9 & $t$-test & -2.15 & 156.63 & $0.03^{*}$ & 0.3 \\
\hline Social support-satisfaction & SSQ-S & 90 & $5.5^{a}$ & $1.2^{\mathrm{b}}$ & 73 & $5.5^{a}$ & $1.3^{\mathrm{b}}$ & MWUT & 3259.50 & & 0.93 & 0.0 \\
\hline Self-efficacy & GSE & 101 & 30.2 & 6.9 & 72 & 31.8 & 3.6 & $t$-test & -2.05 & 158.54 & $0.04^{*}$ & 0.3 \\
\hline Self-esteem & RSES & 96 & 21.4 & 5.7 & 72 & 25.7 & 3.6 & $t$-test & -5.92 & 161.82 & $0.00 *$ & 0.9 \\
\hline Task-oriented coping & CISS-T & 100 & 3.6 & 0.8 & 73 & 4.0 & 0.6 & $t$-test & -3.67 & 170.87 & $0.00 *$ & 0.6 \\
\hline Emotion-oriented coping & CISS-E & 100 & 2.7 & 0.9 & 73 & 2.4 & 0.7 & $t$-test & 2.62 & 166.57 & $0.01 *$ & -0.4 \\
\hline Avoidance-oriented coping & CISS-A & 100 & 2.8 & 0.9 & 73 & 2.7 & 0.8 & $t$-test & 1.23 & 164.15 & 0.22 & -0.1 \\
\hline Sense of coherence & SOC & 100 & 57.5 & 6.9 & 72 & 59.2 & 5.0 & $t$-test & -1.87 & 169.97 & 0.06 & 0.3 \\
\hline
\end{tabular}

Abbreviations: BPI, Brief Pain Inventory; CISS, Coping Inventory for Stressful Situations-21; d.f., degree of freedom; GSE, General Self-Efficacy Scale; HADS, Hospital Anxiety and Depression Scale; IQR, interquartile range; MD, median; MWUT, Mann-Whitney U-test; RNLI, Reintegration to Normal Living Index; RSES, Rosenberg Self-Esteem Scale; SCI, spinal cord injury; SHCS, Scale; IQR, interquartile range; MD, median; MWUT, Mann-Whitney U-test; RNLI, Reintegration to Normal Living Index; RSES,
Self-Report Health Conditions Scale; SOC, Sense of Coherence Scale-13; SSQ, Short-Form Social Support Questionnaire-6. a Median is reported due to a significant Kolmogorov-Smirnov test $(P<0.01)$.

bInterquartile range is reported due to a significant Kolmogorov-Smirnov test $(P<0.01)$

$* P<0.05$.

stepwise model, gender is also significant. Both models were significant overall. The stepwise model improved prediction of group membership by $52 \%$ and the forced-in model by $55 \%$ compared with an empty model, and by $3 \%$ and $6 \%$, respectively, compared with the theory-based approach. The ORs of the independent variables do not differ significantly between the theory-based and the exploratory modelling approaches, as their CIs overlap. None of the models displayed any difficulties with multicollinearity or interdependence of residuals according to the model diagnostics.

\section{DISCUSSION}

This study compared a broad range of biopsychosocial characteristics between an SCI and a specific non-SCI sample. The burden by health conditions, pain, anxiety and depressive symptoms was on average higher in people with SCI than without SCI. Their participation, amount of social support, self-efficacy, self-esteem and coping were lower. The difference between the two samples was consistently explained by four factors: the number of health conditions, pain interference, participation and age. However, the results need to be interpreted with caution as the matching of the samples regarding age and educational level was not fully successful, and the groups with and without SCI differed greatly, for example, in terms of their employment status. Thus, the findings can only provide a first indication about the biopsychosocial outcomes of SCI, beyond the obvious neurological, motor and sensory losses.

The burden imposed by secondary complications points at the importance of health maintenance and secondary prevention following SCI. The significance of pain interference, but not of pain intensity, suggests that if pain is present, it might affect the life of individuals with SCI to a larger degree than that of individuals without SCI. The results suggest that considerable losses in participation may be present in individuals with SCI. Participation is a key outcome in rehabilitation, but this claim is seldom supported by comparative data.

However, attributing the differences between the two samples to SCI alone has to be considered cautiously. The samples not only differed in terms of the presence or absence of SCI, but also differed, for example, by age and employment status, both factors that could explain the findings irrespective of SCI. On the other hand, age has been controlled statistically in the regression analyses. In addition, the measure of participation used in this study included employment combined with questions on leisure activities, family and social involvement, mobility and self-care. Thus, one could argue that differences in employment have also been accounted for. Nevertheless, future research should shed light on the role of meaningful occupation (and the lack thereof) for SCI outcomes in a more differentiated way. In addition, for more valid comparative research, future studies should target representative general population samples as the reference group.

Environmental (social support) and personal factors (self-efficacy, self-esteem, coping, sense of coherence) are supposed to influence functioning and disability, but did not differ between people with or without SCI after multivariate adjustment. Low levels of social support have been shown to be related to mortality, physical and mental health in SCI. Only few studies have compared social support between individuals with and without SCI, and these have reported equivocal results. ${ }^{24}$

Among the personal factors, only the use of task-oriented coping seemed to differentiate in the exploratory analyses. This might reflect the situation dependence of coping strategies described by Lazarus (1993), ${ }^{25}$ who states that task-oriented coping might be of no use in circumstances that are unchangeable (whereas useful in situations that are changeable). The bodily reality of SCI is such an unchangeable circumstance.

Depressive mood, which is an important and frequently reported outcome following SCI, ${ }^{8}$ did not differentiate between the samples in the multivariate analyses. Depression is a major problem in the general population as well; ${ }^{9}$ therefore, it might be possible that SCI does not stand out when secondary conditions, pain and participation problems are taken into account. This assumption can be supported by comparative studies using the SF- $36 .^{26}$ 
Table 4 The $\chi^{2}$-test of the dichotomized study variables

\begin{tabular}{|c|c|c|c|c|c|c|c|c|c|}
\hline Variable & Scale & Cut-offa & & $\mathrm{SCl}, \mathrm{n}$ & Non-SCl, n & $\mathrm{N}$ & $\chi^{2}$ & d.f. & P-value \\
\hline \multirow[t]{2}{*}{ Health conditions-number } & SHCS-N & $<3$ & Less & 24 & 54 & & & & \\
\hline & & $\geqslant 3$ & More & 78 & 19 & 175 & 43.82 & 1 & $0.000 *$ \\
\hline \multirow[t]{2}{*}{ Health conditions-limitations } & SHCS-L & 1 & Absent & 69 & 60 & & & & \\
\hline & & $>1$ & Present & 33 & 13 & 175 & 4.65 & 1 & $0.031^{*}$ \\
\hline \multirow[t]{2}{*}{ Anxiety symptoms } & HADS-A & $\leqslant 4$ & Lower & 44 & 54 & & & & \\
\hline & & $>4$ & Higher & 58 & 19 & 175 & 16.42 & 1 & $0.000^{*}$ \\
\hline \multirow[t]{2}{*}{ Depression symptoms } & HADS-D & $\leqslant 4$ & Lower & 39 & 54 & & & & \\
\hline & & $>4$ & Higher & 63 & 19 & 175 & 21.82 & 1 & $0.000^{*}$ \\
\hline \multirow[t]{2}{*}{ Pain intensity } & BPI-Intens & 0 & No pain & 74 & 43 & & & & \\
\hline & & $>0$ & Pain & 28 & 30 & 175 & 3.58 & 1 & 0.059 \\
\hline \multirow[t]{2}{*}{ Pain interference } & BPI-Interfere & 0 & Absent & 10 & 42 & & & & \\
\hline & & $>0$ & Present & 92 & 31 & 175 & 46.41 & 1 & $0.000 *$ \\
\hline \multirow[t]{2}{*}{ Participation } & RNLI & $\leqslant 92$ & Lower & 73 & 15 & & & & \\
\hline & & $>92$ & Higher & 29 & 58 & 175 & 44.31 & 1 & $0.000 *$ \\
\hline \multirow[t]{2}{*}{ Social support-number } & SSQ-N & $<3$ & Fewer & 69 & 38 & & & & \\
\hline & & $\geqslant 3$ & More & 33 & 35 & 175 & 4.35 & 1 & $0.037^{*}$ \\
\hline \multirow[t]{2}{*}{ Social support-satisfaction } & SSQ-S & $<5.3$ & Less & 53 & 31 & & & & \\
\hline & & $\geqslant 5.3$ & More & 49 & 42 & 175 & 1.54 & 1 & 0.215 \\
\hline \multirow[t]{2}{*}{ Self-efficacy } & GSE & $\leqslant 31$ & Lower & 55 & 34 & & & & \\
\hline & & $>31$ & Higher & 47 & 39 & 175 & 0.92 & 1 & 0.338 \\
\hline \multirow[t]{2}{*}{ Self-esteem } & RSES & $\leqslant 25$ & Lower & 68 & 32 & & & & \\
\hline & & $>25$ & Higher & 34 & 41 & 175 & 9.06 & 1 & $0.003^{*}$ \\
\hline \multirow[t]{2}{*}{ Task-oriented coping } & CISS-T & $\leqslant 3.9$ & Lower & 69 & 30 & & & & \\
\hline & & $>3.9$ & Higher & 33 & 43 & 175 & 12.21 & 1 & $0.000 *$ \\
\hline \multirow[t]{2}{*}{ Emotion-oriented coping } & CISS-E & $\leqslant 2.6$ & Lower & 45 & 48 & & & & \\
\hline & & $>2.6$ & Higher & 57 & 25 & 175 & 8.00 & 1 & $0.005^{*}$ \\
\hline \multirow[t]{2}{*}{ Avoidance-oriented coping } & CISS-A & $\leqslant 2.7$ & Lower & 47 & 36 & & & & \\
\hline & & $>2.7$ & Higher & 55 & 37 & 175 & 0.18 & 1 & 0.672 \\
\hline \multirow[t]{2}{*}{ Sense of coherence } & SOC & $<59$ & Lower & 52 & 32 & & & & \\
\hline & & $\geqslant 59$ & Higher & 50 & 41 & 175 & 0.87 & 1 & 0.351 \\
\hline \multirow[t]{2}{*}{ Age } & & $\leqslant 52$ & Younger & 40 & 45 & & & & \\
\hline & & $>52$ & Older & 62 & 20 & 167 & 14.31 & 1 & $0.000 *$ \\
\hline \multirow[t]{2}{*}{ Gender } & & 0 & Female & 26 & 18 & & & & \\
\hline & & 1 & Male & 76 & 55 & 175 & 0.02 & 1 & 0.900 \\
\hline \multirow[t]{2}{*}{ Years of education } & & $\leqslant 13$ & Shorter & 65 & 28 & & & & \\
\hline & & $>13$ & Longer & 30 & 43 & 166 & 13.86 & 1 & $0.000^{*}$ \\
\hline
\end{tabular}




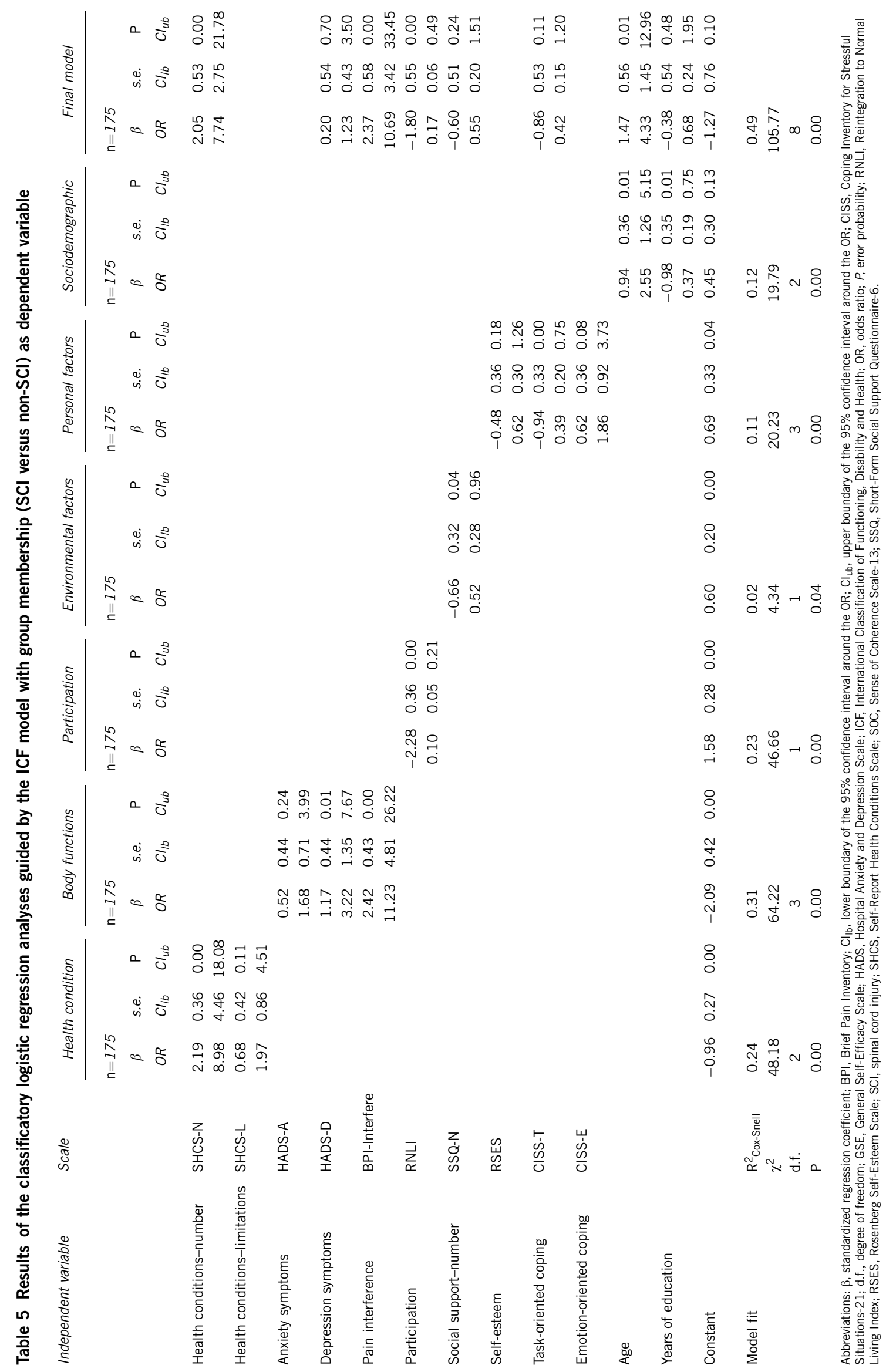


Table 6 Results of the explorative logistic regression analyses with group membership (SCI versus non-SCI) as dependent variable

\begin{tabular}{|c|c|c|c|c|c|c|c|}
\hline \multirow[t]{3}{*}{ Independent variable } & \multirow[t]{3}{*}{ Scale } & \multicolumn{3}{|c|}{ Stepwise model } & \multicolumn{3}{|c|}{ Forced-in model } \\
\hline & & $\mathrm{n}=158$ & & & $\mathrm{n}=158$ & & \\
\hline & & $O R$ & $C l_{I b}$ & $\mathrm{Cl}_{u b}$ & $O R$ & $C l_{l b}$ & $\mathrm{Cl}_{u b}$ \\
\hline \multirow[t]{2}{*}{ Health conditions-number } & SHCS-N & 2.29 & 0.58 & 0.00 & 2.24 & 0.63 & 0.00 \\
\hline & & 9.83 & 3.16 & 30.60 & 9.42 & 2.72 & 32.70 \\
\hline Health conditions-limitations & & 6.76 & 1.62 & 28.20 & 12.06 & 1.88 & 77.50 \\
\hline \multirow[t]{2}{*}{ Anxiety symptoms } & HADS-A & & & & 1.06 & 0.86 & 0.21 \\
\hline & & & & & 2.89 & 0.54 & 15.50 \\
\hline \multirow[t]{2}{*}{ Depression symptoms } & HADS-D & & & & 0.50 & 0.76 & 0.51 \\
\hline & & & & & 1.65 & 0.37 & 7.33 \\
\hline Pain intensity & BPI-Intens & & & & -0.83 & 0.64 & 0.19 \\
\hline Participation & & 0.11 & 0.04 & 0.33 & 0.10 & 0.03 & 0.39 \\
\hline \multirow[t]{2}{*}{ Social support-number } & SSQ-N & & & & -0.96 & 0.63 & 0.13 \\
\hline & & & & & 0.38 & 0.11 & 1.31 \\
\hline \multirow[t]{2}{*}{ Social support-satisfaction } & SSQ-S & & & & 0.21 & 0.67 & 0.76 \\
\hline & & & & & 1.23 & 0.33 & 4.59 \\
\hline \multirow[t]{2}{*}{ Self-efficacy } & GSE & & & & 0.94 & 0.71 & 0.19 \\
\hline & & & & & 2.56 & 0.64 & 10.30 \\
\hline \multirow[t]{2}{*}{ Self-esteem } & RSES & & & & 0.87 & 0.74 & 0.23 \\
\hline & & & & & 2.40 & 0.57 & 10.10 \\
\hline \multirow[t]{2}{*}{ Task-oriented coping } & CISS-T & -1.80 & 0.63 & 0.00 & -2.23 & 0.76 & 0.00 \\
\hline & & 0.17 & 0.05 & 0.57 & 0.11 & 0.02 & 0.48 \\
\hline Emotion-oriented coping & CISS-E & & & & -0.52 & 0.68 & 0.44 \\
\hline Gender & & 3.60 & 1.06 & 12.20 & 2.75 & 0.71 & 10.60 \\
\hline \multirow[t]{2}{*}{ Years of education } & & & & & 0.63 & 0.79 & \\
\hline & & & & & 0.85 & 0.24 & 2.93 \\
\hline Constant & & -2.87 & 0.91 & 0.00 & -3.71 & 1.33 & 0.01 \\
\hline & & 0.06 & & & 0.02 & & \\
\hline Model fit & $\mathrm{R}^{2}$ Cox-Snell & 0.52 & & & 0.55 & & \\
\hline & $\chi^{2}$ & 115.34 & & & 124.74 & & \\
\hline & d.f. & 7 & & & 18 & & \\
\hline & $\mathrm{P}$ & 0.000 & & & 0.000 & & \\
\hline
\end{tabular}

Abbreviations: $\beta$, standardized regression coefficient; $\mathrm{BPI}$, Brief Pain Inventory; $\mathrm{Cl}_{\mathrm{Ib}}$, lower boundary of the $95 \%$ confidence interval around the OR; $\mathrm{Cl}_{\mathrm{ub}}$, upper boundary of the $95 \%$ confidence interval around the OR; CISS, Coping Inventory for Stressful Situations-21; d.f., degree of freedom; GSE, General Self-Efficacy Scale; HADS, Hospital Anxiety and Depression Scale; ICF, International Classification of Functioning, Disability and Health; OR, odds ratio; $P$, error probability; RNLI, Reintegration to Normal Living Index; RSES, Rosenberg Self-Esteem Scale; SCI, spinal cord injury; SHCS, Self-Report Health Conditions Scale; SOC, Sense of Coherence Scale 13; SSQ, Short-Form Social Support Questionnaire-6.

Overall, depressive symptoms, social support and personal factors might be determinants explaining the variation of the key outcomes, pain, secondary conditions and participation, in both the SCI and non-SCI-samples similarly.

For the current study, a number of limitations apply. The 102 study participants with SCI represent a self-selected convenience sample. Selecting the comparison group from the staff of the rehabilitation facilities must be questioned, as they cannot be regarded representative for the general population. In addition, the attempt to match the SCI and the non-SCI sample according to age and education level proved to be difficult. Furthermore, the occupational situation of the SCI and the comparison group differed fundamentally. The representativity of the study sample and the generalizability of the results can be questioned because of the low response rates. In the logistic regression analyses, the cutoffs for dichotomization were largely data driven, and might have led to more pronounced results than calculations based on 
the original continuous data. However, the analyses strategy used has the advantage that the underlying assumptions for regression modelling (for example, the linearity of the relationships) are more easily fulfilled, and produce robust results.

\section{CONCLUSION}

Overall, the findings of this study provide some support for current clinical practice, which sets the prevention of secondary conditions, effective pain treatment and optimizing participation as major goals in clinical as well as community-based rehabilitation. In addition, to deal more effectively with the consequences of SCI, it might be beneficial to strengthen potential buffering resources like social support, selfefficacy, self-esteem and coping.

\section{DATA ARCHIVING}

There were no data to deposit.

\section{CONFLICT OF INTEREST}

The authors declare no conflict of interest.

\section{ACKNOWLEDGEMENTS}

This study was funded by the Swiss Paraplegic Research (SPF), Nottwil, Switzerland. We thank all study participants for their most valuable contribution. We are also indebted to the clinic directors Professor Armin Curt (Balgrist Zurich), Mark Mäder (Rehab Basel) and Beat Villiger (SPZ Nottwil) for their commitment to the study; to the local research coordinators Hansjörg Lüthi (Rehab Basel) and Gabi Müller (SPZ Nottwil); and to the human resources personnel, and in particular Reto Schmid (SPZ Nottwil), for their support of the data collections.

1 World Health Organization. International Classification of Functioning, Disability and Health. World Health Organization: Geneva, 2001.

2 Teasell R, Mehta S, Aubut JAL, Foulon BL, Wolfe DL, Hsieh JTC et al. Pain following spinal cord injury. Arch Phys Med Rehabil 2010; 91: 816-831.

3 Orenczuk S, Slivinski J, Mehta S, Teasell RW. Depression following spinal cord injury. Spinal Cord Injury Rehabilitation Evidence (SCIRE). Version 3.0 2010; http://www. scireproject.com/sites/default/files/depression.pdf. Accessed 12 September, 2011.

4 Tzonichaki I, Kleftaras G. Paraplegia from spinal cord injury: self-esteem, loneliness, and life satisfaction. Occup Participation Health 2002; 22: 96-103.

5 Bickenbach JE, Chatterji S, Badley EM, Üstün BT. Models of disablement, universalism and the international classification of impairments, disabilities and handicaps. Soc Sci Med 1999; 48: 1173-1187.
6 Dijkers M, Bryce T, Zanca J. Prevalence of chronic pain after traumatic spinal cord injury: a systematic review. J Rehabil Res Dev 2009; 46: 13-29.

7 Bouhassira D, Lanteri-Minet M, Attal N, Laurent B, Touboul C. Prevalence of chronic pain with neuropathic characteristics in the general population. Pain 2008; 136: 380-387.

8 Galvin LR, Godfrey HP. The impact of coping on emotional adjustment to spinal cord injury $(\mathrm{SCl})$ : review of the literature and application of a stress appraisal and coping formulation. Spinal Cord 2001; 39: 615-627.

9 Kessler RC, Berglund P, Demler O, Jin R, Merikangas KR, Walters EE. Lifetime prevalence and age-of-onset distributions of DSM-IV disorders in the national comorbidity survey replication. Arch Gen Psychiatry 2005; 62: 593-602.

10 Kennedy P, Rogers BA. Anxiety and depression after spinal cord injury: a longitudinal analysis. Arch Phys Med Rehabil 2000; 81: 932-937.

11 Rintala D, Young ME, Hart KA, Fuhrer MJ. The relationship between the extent of reciprocity with social supporters and measures of depressive symptomatology, impairment, disability, and handicap in persons with spinal cord injury. Rehabil Psychol 1994; 39: 15-27.

12 Wellman B, Gulia M. The network basis of social support: a network is more than the sum of its ties. In: Wellman B (ed). Networks in the Global Village: Life in Contemporary Communities. Westview Press: Boulder, C0, 1999, pp 83-118.

13 Post M, Van Dijk A, Van Asbeck F, Schrijvers A. Life satisfaction of persons with spinal cord injury compared to a population group. Scand J Rehabil Med 1998; 30: 23-30.

14 Benony H, Daloz L, Bungener C, Chahraoui K, Frenay C, Auvin J. Emotional factors and subjective quality of life in subjects with spinal cord injuries. Am J Phys Med Rehabil 2002; 18: 437-445.

15 Nicotra A, Ellaway PH. Thermal perception thresholds: assessing the level of human spinal cord injury. Spinal Cord 2006; 44: 617-624.

16 Cleeland CS. Measurement of pain by subjective report. In: Chapman CR, Loeser JD (eds). Advances in Pain Research and Therapy, Volume 12: Issues in Pain Measurement. Raven Press: New York, 1989, pp 391-403.

17 Zigmond AS, Snaith RP. The hospital anxiety and depression scale. Acta Psychiatr Scand 1983; 67: 361-370.

18 Wood-Dauphinee SL, Opzoomer MA, Williams JI, Marchand B, Spitzer WO. Assessment of global function: the reintegration to normal living index. Arch Phys Med Rehabil 1988; 69: 583-590.

19 Sarason IG, Levine HM, Basham RB, Sarason BR. Assessing social support: the social support questionnaire. J Pers Soc Psychol 1983; 44: 127-139.

20 Jerusalem M, Schwarzer R. Selbstwirksamkeit. In: Schwarzer R (ed). Skalen zur Befindlichkeit und Persönlichkeit Forschungsbericht 5 der FU Berlin. FU Berlin: Berlin, 1981, pp 15-28.

21 Rosenberg M. Society and the Adolescent Self-Image. Princeton University Press: Princeton, NJ, 1965.

22 Endler NS, Parker JDA. Coping Inventory for Stressful Situations (CISS): Manual. MultiHealth Systems: Toronto, 1990.

23 Antonovsky A. The structure and properties of the sense of coherence scale. Soc Sci Med 1993; 36: 725-733.

24 Müller R, Peter C, Cieza A, Geyh S. The role of social support and social skills in people with spinal cord injury - a systematic review of the literature. Spinal Cord 2011; 50: 94-106.

25 Lazarus RS. Coping theory and research: past, present, and future. Psychosom Med 1993; 55: 234-247.

26 Post M, Noreau L. Quality of life after spinal cord injury. J Neurol Phys Ther 2005; 29: 139-146. 